\title{
Художественно-функциональная специфика хронотопа в прозе Германа Гессе
}

\begin{abstract}
Аннотация: Данная работа имеет целью исследование особенностей хронотопа художественного наследия немецкого писателя Германа Гессе, который использует систему пространственных и временнъх ориентиров в процессе решения антропологических и онтологических проблем. Если пространственные отношения показаны через разные виды движения и художественное исследование пространства позволяет писателю решать антропологические проблемы, то категория времени занимает немецкого художника слова в связи с онтологической проблематикой, в частности, делается попытка средствам литературы изучить соотнесённость категорий духовного, временного и культурного. К тематике, характеристикам и образам пространства писатель обращается при характеристике аксиосферы личности, при описании отдельных психологических состояний и процессов, а также при выявлении вектора развития внутреннего мира человека. Проблему времени немецкий писатель ставит и решает в онтологическом ключе. Противопоставляя время и безвременье (вечность), писатель утверждает существование мира вечной, чистой, творческой, божественной духовности, с которым соотнесены бытие культуры и бытие личности.

Review: The purpose o the present article is to study special features of the chronotope of artistic heritage of Hemann Hesse who used the system of spatial and time references in the anthropological and ontological decision making process. Hesse expressed spatial relations in different forms of movement and his researches of space allowed him to solve anthropological issues while his researches of time allowed the German master of the pen to solve ontological problems. In particular, he attempted at studying the relation between the spiritual, the temporal and the cultural by literary expressive means. The writer touches upon the subject, features and images of space when describing axiosphere of personality or psychological states or processes or studying the vector of development of development of the human inner world. As for the time, the German writer brought forth and solved that problem in terms of ontology. Opposing time to timelessness, the German writer proved the existence of the eternal, pure, creative and divine spirituality and compared it to the existence of culture and personality.
\end{abstract}

Ключевые слова: культурология, философия культуры, антропология, хронотоп, пространство, время, движение, личность, бытие культуры, проза.

Keywords: cultural research, philosophy of culture, anthropology, chronotope, space, time, movement, personality, existence of culture, prose.

И зучение категорий пространства и времени междисциплинарно: физик, лингвист, психолог, биолог, культуролог, философ пытаются проникнуть в тайну главного, если не единственного человеческого ресурса, отплатить природе за страх смерти, раздвинуть границы бытия.

Искусство не делает попыток «вскрыть» часовой механизм Вселенной, но вносит посильный вклад в наблюдения за его работой и экспериментирует с пространственными эффектами. Художественные произведения могут быть условно разделены на две большие, но неравнозначные по объёму группы. В первую можно включить произведения, в которых проблема пространства-времени «заявлена» в названии или композиции наглядно и, следовательно, является центральной: картина Сальвадора Дали «Постоянство времени», «Сказка о потерянном времени» Евгения Шварца, «Время, вперёд!» Валентина Катаева и Георгия Свиридова - лишь немногие, но достаточно яркие примеры. Группу гораздо более обширную исторически и жанрово составляют произведения, в которых пространственно-временные отношения и характеристики вплетены в ткань изобразительно-выразительных средств и составляют художественное своеобразие авторского 
стиля, позволяют проникнуть в мировоззренческие установки художника.

Возникновение и использование в культурологии, философии и филологии понятия «хронотоп» не только фиксирует определённый уровень развития этих областей знания, но и подчёркивает идею неразрывности пространственно-временного в представлениях современного человека. Изучение особенностей «поведения» хронотопа у писателей разных эпох и культур позволяют, с одной стороны, peконструировать их мировоззрение, с другой стороны - углубить и уточнить свои представления о соответствующем типе культуры. Так, психология и парадигматика постмодерна не возникли на пустом месте, их подготовили модернистское сознание и социокультурная практика.

Обращение к культуре и искусству первой половины XX в. представляет богатый материал для осознания того, как быстро усложняется внутренняя жизнь личности, как многократно опосредованы процессы социальных взаимодействий, как возрос информационно-идеологический гнёт с момента «заката Европы», провозглашённого, но не совершившегося в полной мере (кстати, и образ заката также имеет пространственно-временное наполнение).

Данная работа имеет целью исследование особенностей хронотопа художественного наследия немецкого писателя Германа Гессе, который использует систему пространственных и временных ориентиров в процессе решения антропологических и онтологических проблем. Внутренний мир человека в произведениях немецкого классика часто описывается пространственно: можно погрузиться «на дно ощущений», можно метаться от одного чувства или состояния к другому, можно остро переживать границы своего «я» - применяя этот художественный приём, Г. Гессе не является новатором. Более необычно и интересно другое. Будучи убеждённым идеалистом (писатель многократно в произведениях разных жанров отстаивал примат духовного, фантезийного над реальностью, действительностью, материальностью), писатель неразрывно связывает человеческое бытие с движением. Стабильный интерес к философии, который Гессе проявлял всю жизнь, позволил ему не только учесть мнение Аристотеля, Плутарха, Б. Паскаля, Ж.-Ж. Руссо, Дж. Локка о пользе и онтологической необходимости движения. В произведениях Гессе движение приобpeтает статус духовной экзистенции творческой личности.

Критические, негативные состояния души и Духа писатель метафоризирует через образы животных, попавших в клетки; чувство безысходности, вялости, острого недовольства собой и миром для его героев - это невозможность двигаться, жить «без высокой цели, без жажды, без подъёма» или «в пещере страха». Обретение границ или сжатие пространства внутреннего бытия всегда связаны с какими-либо потерями, проблемами (например, именно в таком плане в автобиографических произведениях описывается взросление как болезненный процесс отпадения от свободы и счастья). В свою очередь, позитивные, светлые чувства неразрывно связаны с движением, например, «благодарное странствие вдвоём по стране дружбы» или возможность «взлететь в небеса и увидеть Бога за работой». В романе «Курортник» есть любопытнейший, полный истинной страсти и искренности монолог главного героя с буржуа, которые не действителен, так как не живёт, а существует «в бумажной плоскости денег и кредита, морали, закона, духа, почтенности...» ${ }^{1}$ Этот уважаемый обществом человек в статике категорического императива, добродетели и разума далёк от истинного бытия, в котором пребывают камни, птицы, деревья, животные. Бытие в представлении писателя реализует свою креативность в движении. Герои произведений Германа Гессе - это путешественники, либо сознательно избирающие путь скитальцев, бродяг, идущих без цели, но обретая и осознавая её в пути, либо отправляющиеся в путь, когда невозможно сохранять старое положение вещей, продолжать старую жизнь и себя в ней. В произведениях разных лет и разной тематики можно найти мотивы поэтизации странничества, образы бродяг вырастают в светлые и почтительные образы пилигримов, почти святых страдальцев:

${ }^{1}$ Гессе $Г$. Собрание сочинений в 4-х томах [Текст] / Г. Гессе; пер. с нем. - СПб.: Северо-запад, 1994. T.2, C. 174 . 
«Они - сыны Адама, изгнанного из рая, и братья зверей невинных. Из рук неба берут они час за часом то, что им даётся: солнце, дождь, туман, снег, тепло и стужу, благополучие и нужду...Бродяга...всегда живёт первый день, всегда руководствуясь простыми желаниями и нуждами». ${ }^{2}$

Причина этого «пространственного беспокойства» глубоко укоренена в убеждённости писателя в том, что «...в безопасный путь посылают только слабых» и в том, что «каждый из нас лишь человек, лишь попытка, лишь нечто куда-то движущееся». ${ }^{3}$ Скитания героев Г. Гессе - это развёрнутая пространственная метафора их духовных поисков. Даже медитация описывается как способ «указать индивидууму своё место», т.е. назначение, смысл бытия.

Направление и цель этого движения писатель обозначает во многих произведениях как путь к совершенству, в область чистой духовности, которая либо принимает вид дополнительного измерения в жизни развитой, выпавшей из стандарта личности, либо обозначается как область вечности, куда человек может прорваться в процессе духовной деятельности. При этом разные виды движения оказываются более или менее состоятельными именно в плане духовного роста: в произведениях Германа Гессе представлены движение хаотическое, циклическое, линейное горизонтальное, линейном вертикальное, движение вглубь и вскользь упоминается движение по спирали.

Включая персонаж в тот или иной вид движения, писатель размышляет над онтологическими «показателями» движения как такового, одновременно наблюдая за метаморфозами человеческой души. Так, в рассказе «Индийская судьба» Даса и его жена Правати, движимые страстями, погружены в хаос любви, ненависти, соперничества, борьбы за власть. Итог их существования ужасен, несмотря на то, что их жизнь - лишь навеянный сон. Можно ли считать хаотическое движение лишённым значения? Над этим вопросом

\footnotetext{
${ }^{2}$ Гессе $Г$. Собрание сочинений в 4-х томах [Текст] / Г. Гессе; пер. с нем. - СПб.: Северо-запад, 1994. T.4, C. 164 .

${ }^{3}$ Гессе $Г$. Собрание сочинений в 4-х томах [Текст] / Г. Гессе; пер. с нем. - СПб.: Северо-запад, 1994. T.4., C.74-75.
}

писатель продолжает размышлять в других текстах. Хаотичны бродяжничество Кнульпа и Гольдмунда (герои повестей «Кнульп», «Нарцисс и Гольдмунд»), любовных историй и приключений в их жизни ничуть не меньше, но один из них поёт песни, радует людей весёлыми историями, а другой ищет вдохновения, любуюсь красотой мира. Движение без чёткого направления в этих повестях реабилитировано, оно лучше статики мещанского быта и бытия, в нём есть надежда на становление, эти лягушки могут сбить хотя бы небольшой кусочек масла в своем кувшине.

В повести «Сиддхардтха» Гессе апробирует циклическое движение, которое позволяет ему решить двуединую задачу: развенчать идею заимствования знания и отстоять право личности на сугубо индивидуальный путь развития. Главный герой повести - это одна из многочисленных проекций личности автора, носитель восточной мудрости, для которого образ вращающегося колеса сансары так же привычен и естественен, как образ Девы Марии для христианина. Вырваться из череды коловращений - нелёгкая задача, эту цель ставят многие. Но вращается и колесо аскезы, размышления, отстранения от собственной сущности: заимствованная мудрость не позволяет развиваться, потому что «мудрость непередаваема», она постигаема и переживаема каждым индивидуально. Отвергнув циклическое движение с его повторяемостью привычного и безысходностью чужеродного, Гессе провозглашает ценностный плюрализм, которым через несколько десятилетий расцветёт эпоха постмодерна. Бег по кругу - это хождение чужими путями, как бы прекрасны и возвышенны они не были, даже в области духовного бытия.

Горизонтальные перемещения персонажей в рамках хронотопа обычно отражают их мировоззренческие поиски и призваны решить важную личностную проблему: поиски самого себя. Неотъемлемым исходно-конечным пунктом путешествия через преодоление «родительских», традиционалистских ценностей часто является дом, величайший оплот души, где отцвёл рай детства, светлых мечтаний и близости с природой. Возвращение домой - это вариант циклического движения, в котором, тем не менее, есть высший смысл. Правда, в 
иные моменты творчества путь назад - это саморазрушение вплоть до самоубийства. Вернуться «к матери, к Богу, к Вселенной» - это путь самоубийц, не способных справиться с жизнью и готовых «вернуться к началу». 4

Путешествия - это путь к духовному самообретению, которое в свете традиций психоанализа приобретает иные пространственные контуры, требуют и иного типа движения - это движение вглубь, к самости, к центру личности как высочайшей цели самопознания. Здесь Гессе достаточно изящен, но находится под огромным влиянием учения 3. Фрейда и К. Г. Юнга. Метафоры глубины мира и человеческой души демонстрируют органическую переплетённость онтологической и гносеологической проблем: для Германа Гессе «окунуться в мир» - это жить в нём и познать его. Важен не только сам по себе путь, важно качество бытия: «Не там глубина мира и его тайн, где облачно и черно, глубина в прозрачно-весёлом». ${ }^{5}$ И не только потому, что радость - свойство Божьего присутствия; светлую чистую радость так трудно удерживать в пространстве души, так трудно сохранять ей верность в испытаниях и тяготах бытия. Приверженность немецкого писателя идеям всеединства и влияние диалектики на его творчество сказываются в его регулярных попытках «отрабатывать» разные функционалы одного типа движения. Так, путь вниз, вглубь - это инвариант предсмертного пути (в стихотворениях сборника «Кризис», повести «Клейн и Вагнер», романе «Игра в бисер» уход вглубь «мутного потока» бытия - и смерть, и жизненная необходимость).

Весьма показательно, что в последнем своём великом произведении - романе «Игра в бисер» немецкий писатель отправляет главного героя Йозефа Кнехта в последнее путешествие, когда тот понял экзистенциальную и историко-культурную ограниченность своей духовной вотчины, Касталии, с её игрой и нежеланием noгружаться в реальность, перемешиваться и растворяться в ней. Когда духовное движение и развитие в рамках какой-либо

\footnotetext{
${ }^{4}$ Гессе Г. Степной волк [Текст] / Г. Гессе; пер. с нем. - Спб, Азбука - классика, 2004Г. - С. 61.

${ }^{5}$ Гессе Г. Собрание сочинений в 4-х томах [Текст] / Г. Гессе; пер. с нем. - СПб.: Северо-запад, 1994. T. 4 , C. 300.
}

формы культуры оказывается исчерпанным, личность покидает искусственно созданное пространство и погружается в мир,

который «полон становления, полон истории, полон попыток и вечно новых начал, ... он родина всех судеб, всех взлётов, всех искусств, всякой человечности...», ${ }^{6}$ поэтому достоин любви и восхищения. Мир людей прекрасен, потому что он неизменно и всесторонне движется, получая надежду на обновление и великие победы Духа, свободно играющего смыслами и их воплощениями. Представляется важным отметить, что в приведённой цитате история, время оказываются реабилитированы, но так в мировоззрении и творчестве Г. Гессе было не всегда. Если пространственные отношения показаны прежде всего через разные виды движения и художественное исследование пространства позволяет писателю решать антропологические проблемы, то категория времени занимает немецкого художника слова в связи с онтологической проблематикой, в частности, делается попытка средствам литературы изучить соотнесённость категорий духовного, временного и культурного.

К самому времени Гессе настроен достаточно критично и крайне противоречиво. Писатель то заявляет, что время нереально, то подчёркивает, что «великое время поднимает маленького индивида выше его будничных возможностей и удесятеряет его силы ${ }^{7}$, то пишет, что наш мир обезумел «под властью золота, числа и времени» и указывает на «безжалостную мощь» последнего. Причина сложного отношения ко времени у писателя имеет серьёзные психологические и экзистенциальные причины, хотя именно в этом вопросе кроется наиболее глубокое противоречие в сущности его хронотопа. Дело в том, что время - злейший враг красоты земной, которой в юности и молодости автор благоговейно восхищался: в его произведениях любовно описываются чашечка цветка, женское ушко, горное озеро на рассвете и т.д. Искреннее

${ }^{6}$ Гессе $\Gamma$. Собрание сочинений в 4-х томах [Текст] / Г. Гессе; пер. с нем. - СПб.: Северо-запад, 1994. T. 4 , C. 383

7 Гессе $\Gamma$. Собрание сочинений в 4-х томах [Текст] / Г. Гессе; пер. с нем. - СПб.: Северо-запад, 1994. T.3, C. 279. 
восхищение разными появлениями красоты у молодого писателя переплетается с возмущением от сознания бренности всего живого и прекрасного, вплоть до великих достижений культуры. Поэтому время - это ловушка, плен, западня, из которой человеку надо бежать. Путей несколько, они позволяют решить проблему освобождения по-разному и подходят разным типам личностей. Люди спорят со временем, занимаясь искусством, которое само по себе есть способ победить бренность земной красоты. Этот путь для людей того же типа, что и сам Гессе, для «дремлющих на груди матери», любимцев природы, для художников, умеющих увидеть вечное в быстро вянущем и преходящем. Для других, «бодрствующих в пустыне», путь служения Духу и великим традициям, путь аскезы (будь то христианство или Игра в бисер, не имеет значения), медитации. Но все эти пути объединены одним - возможностью отчасти победить время, точнее, страхи человека перед его величием и необратимостью.

Неоднократно в течение творческой деятельности Герман Гессе пишет о попытках человека прорваться в «безвременность», в вечность, но наиболее рельефно проблематика хронотопа проступает в трёх произведениях «Сиддхардтха», «Степной волк» и «Игра в бисер». В повести «Сиддхардтха» продемонстрированы, на наш взгляд, несколько утилитарные представления о времени как ресурсе духовного движения. Главный герой в течение жизни несколько раз круто менял содержание и форму бытия (не каждому удаётся побывать и аскетом-саманой, и пообщаться с Буддой, побыть любовником и азартным игроком и т.д.) Осознав, что в духовном отношении он быстро катится вниз, Сиддхардтха понял самое важное: «Многие годы понадобились мне, чтобы утратить дух, опять разучиться мыслить, забыть единство. Ведь я медленно, извилистыми путями стал из мужчины ребёнком, из мыслителя - ребячливым человеком...", ${ }^{8}$ чтобы начать сначала. Но это было условием жизни души: не изведав отчаяния, невозможно достичь просветления. В этой же повести Гессе по сути отрицает объективный

\footnotetext{
${ }^{8}$ Гессе Г. Сиддхардтха [Текст] / Г. Гессе; пер. с нем. Н Федоровской. - М.:АСТ, 2009. - С. 121.
}

характер времени. Вслед за Блаженным Августином, которого писатель почитает глубоко и преданно, он утверждает, что «...всё живо здесь и сейчас», а прошлое и будущее - лишь иллюзии. Описывая гармоничное бытие, писатель акцентирует его как отрешённое от мыслей о времени, потому что время - это страх, страдание, а всё тягостное, враждебное в мире оказывается побеждённым, стоит лишь отрешиться от мыслей от времени.

В романе «Степной волк» писатель отрицает время, так сказать, практически, предоставляя своему герою Гарри Галлеру (в миру Герман Гессе) возможность пообщаться с Гёте и Моцартом. Выходы за пределы нашего времени-пространства описаны и в других произведениях: в «Индийской судьбе», «Нарциссе и Гольдмунде», но это лишь упоминания, а в «Степном волке» описан механизм и цели. И, самое главное, писатель «колдует» над тем, что такое вечность, будь она всем доступна!

Важно, что в этом нашумевшем в своё время романе отстаивается краеугольная для Гессе идея единства, целостности мира, который «сам по себе не знает ни верха, ни низа», ${ }^{9}$ ни инстинкта, ни Духа, ни человека, ни зверя в их полной разделённости и жёстко детерминированной противопоставленности. Расширение пространства души, способность вместить в себя всё и все проявления бытия - к этому может и должен стремиться человек, но объять Вселенную - значит стать Богом. По мнению Гессе, родиться - значит отделиться от вселенной и отграничиться от Бога, а стать поистине великим - страдая, расширять свою душу навстречу миру и отказаться от тягостной обособленности, соединиться с миром. В этом романе немецкого писателя жизнь человеческой души отчётливо пространственна, $а$ пространство антропологично. При этом человеческая экзистенциальность обречена бороться со временем, а в сущностно-онтологическом измерении (вечности) пребывают Бог, бессмертные и музыка. Описывая вечность, Гессе фрагментарен, ему удалось рассмотреть лишь то, что вечность - это царство истины, куда входят «музыка Моцарта и стихи великих поэтов, в неё входят святые, творившие

9 Гессе Г. Степной волк [Текст] / Г. Гессе; пер. с нем. - Спб, Азбука - классика, 2004. - С. 72. 
великие чудеса, претерпевшие мученическую смерть и давшие людям великий пример. Но точно так же входит в вечность образ каждого настоящего подвига, сила каждого настоящего чувства, даже если никто не знает о них, не видит их, не запишет и не сохранит для потомства. В вечности нет потомства, а есть только современники». ${ }^{10}$ Понимание вечности в этом контексте расширительно, человеку предоставляется возможность пожертвовать собой, создать нечто прекрасное, совершить великое - и прорвать завесу экзистенциальности. Правда, не описываются ни сам момент перехода, ни условия отбора в категорию бессмертных, но немецкого классика всё же греет мысль о возможности избежать смерти в её окончательном варианте. Интересно, что вечность предстаёт в данном случае как особая форма загробного воздаяния в обход традиционных христианских представлений о вечном страдании/блаженстве.

Может показаться, что путь в вечность подозрительно прост, на самом деле пространство мещанского бытия держит нас достаточно крепко, попасть в царство «по ту сторону времени и видимости» даже желание есть не у всех! А что говорить о решимости...Правда, разгадка этого царства даже как-то слишком проста - это и царство человеческой души одновременно. Тоска по иной действительности как будто мешает нам понять, что вечность обитает в нас самих, что мы рождены для счастья и подвига, а живём в вечном недовольстве собой и окружающим миром. Соотнесение души и вечности характерно для религиозного мировоззрения, от влияния которого Гессе так полностью и не освободился, отвергнув лишь его поверхностные, отжившие наслоения и переосмысливая догмат о бессмертии души.

Ещё одним атрибутом вечности у Гессе служит смех бессмертных, звучащий громовыми раскатами в романе «Степной волк». Возможно, этот смех аллюзивен гомеровскому смеху небожителей, но имеет особую мировоззренческую ценность. Судьба Гессе-писателя и Гессе-человека достаточно сложно во многих отношениях: достаточно упомянуть о двух мировых войнах, вынужденном отъезде из Герма-

\footnotetext{
${ }^{10}$ Гессе Г. Степной волк [Текст] / Г. Гессе; пер. с
} нем. - Спб, Азбука - классика, 2004. - С. 196. нии по причине открытой угрозы жизни в годы фашизма, длительных финансовых трудностях и болезнях. Стремление сохранить бодрость духа и способность радоваться крупицам красоты в эпоху, когда мир, казалось, сходил с ума - это удел недюжинной души. Весёлость или попытки прикоснуться к ней хотя бы в мечтах - это психологическая реакция на недостаток радости реальной, событийной, именно она должна быть в вечности, иначе та потеряет свою ценность.

В романе «Степной волк», написанного под сильнейшим влиянием ницшевского «Заратустры», Гессе определяет ту же цель, что и его великий кумир: человек лишь мостик между своим прошлым и великим будущим. Конечно, не поставишь знака равенства между бессмертными Гессе и сверхчеловеком Ницше, но художественный эксперимент писателя «по следам» великого философа дал конкретные культурно-исторические результаты. Хронотоп путешествия в произведениях Г. Гессе продемонстрировал читателям исход из традиций христианской культуры и великой европейский цивилизации. Новые традиции придётся выстраивать и завоёвывать в пути, вечность не откроется сама. Путь человечества к бессмертию попрежнему узок, но он существует, о чём ещё раз задумывается великий писатель в своём самом известном и самом экспериментальном романе «Игра в бисер».

Проблема времени для Гессе тесно связана с проблемой бытия культуры. Размышляя об относительной ценности любых достижений человека и человечества в художественных и публицистических произведениях разных лет, писатель оценивает и свой вклад в литературную копилку человечества. Для писателя история человечества - явление грязное, полное безнравственных поступков и проявлений духовной низости и лености, а вневременной характер бытия Духа - это лишь открытая для человека возможность совершить «бегство из плена времени», выйти «из ничтожества своих инстинктов». В романе «Игра в бисер» категории духовного, божественного, вневременного, творческого существуют по ту сторону от времени и человека. Но то, что признано вечным, классическим в истории культуры, вечно лишь с учётом про- 
должительности жизни одного человека. Мутный поток истории поглотит великие творения культуры, но Дух будет праздновать своё бытие вечно, по-настоящему вечно и создаст много такого, о чём Он сам не подозревает.

Любопытно, что в поздних романах, рассказах, публицистических произведениях Г. Гессе в некотором смысле реабилитирует реальность, историю, человеческую деятельность, хотя они не стали менее противоречивыми или высоко духовными. Вряд ли можно однозначно отнести это за счёт возрастных, социальных или иных изменений, произошедших с писателем. Очевидно, что мировоззренчески зрелому Гессе ближе человеческая экзистенциальность со всей её неоднозначностью. Не утратив известной рафинированности и эстетизма, Герман Гессе приходит к выводу, что «абстракции восхитительны, но дышать воздухом и есть хлеб тоже надо». ${ }^{11}$ Культура в этом смысле должна быть, с одной стороны, обращена в прошлое, к его великим образцам (людям и произведениям), с другой стороны, должна смотреть в будущее. Человек же в любых испытаниях может и должен сохранять весёлую бодрость, ожидая и приближая новые празднества Духа, которые неизбежны по Его вечности и неизбывной энергичности.

Хронотоп в произведениях Гессе функционален, что характерно для произведений постклассического искусства, к которому тяготеет писатель. Хронотоп не самодостаточен, пересечения пространства и времени не изображаются в чистом виде, а занимают важное место в иерархии изобразительно-выразительных средств. Уровень «владения» пространственновременным инструментарием при решении художественно-мировоззренческих задач у Германа Гессе можно сравнить, например, с мастерством Ф.М. Достоев-

\footnotetext{
${ }^{11}$ Гессе $Г$. Собрание сочинений в 4-х томах [Текст] / Г. Гессе; пер. с нем. - СПб.: Северо-запад, 1994. T. 4 , C. 265 .
}

ского, что говорит об уровне писательской одарённости вообще.

Опираясь на наследие М.М. Бахтина, исследовавшего «хронотопические ценности разных степеней и объемов» ${ }^{12}$, мы считаем возможным сделать вывод о некоторых особенностях хронотопа в творчестве великого немецкого писателя первой половины ХХ в. Пространство и время имеют в творческом наследии Германа Гессе разный художественный и функциональный статус. К тематике, характеристикам и образам пространства писатель обращается при решении экзистенциально-антропологических проблем:

- при определении свойств личности, её аксиосферы;

- при характеристике отдельных психологических состояний и процессов;

- при выявлении вектора развития внутреннего мира человека;

Проблему времени немецкий писатель ставит и решает в онтологическом ключе. Противопоставляя время и безвременье (вечность), писатель утверждает существование мира вечной, чистой, творческой, божественной духовности, с которым соотнесены бытие культуры и бытие личности. Личность способна обрести бессмертие, создав нечто значимое в культурно-историческом масштабе. Пропуском в вечность могут стать великое произведение искусства, религиозный или иной подвиг, истинные любовь и самопожертвование как примеры величия человеческой души. Но всё это возможно лишь на пути самопознания, которое неразрывно связано с различными видами движения. Таким образом, в рассмотренном художественном хронотопе решение важнейшей жизненной задачи - выход человека за границы времени - детерминирован пространственными перемещениями.

\footnotetext{
${ }^{12}$ Бахтин, M. М. Вопросы литературы и эстетики. Исследования разных лет / М. М. Бахтин. М.: Худож. лит., 1975. - С. 447-483.

Бахтин, М. М. Собрание сочинений: науч. издание / М. М. Бахтин. - М.: Русские словари, 1996 - Т. 6 : Проблемы поэтики Достоевского. Работы 1960-х - 1970-х гг.: науч. изд.. - 2002. - 800 с. Бахтин, M. М. Формы времени и хронотопа в романе: очерки по исторической поэтике // Бахтин М. М. Вопросы литературы и эстетики. - М.: Худож. лит., 1975. - С. 234-407. - Режим доступа : http://philologos.narod.ru/bakhtin/ hronotop/hronmain.html.
} 


\section{Список литературы:}

1. Бахтин, М. М. Вопросы литературы и эстетики. Исследования разных лет / М. М. Бахтин. М.: Худож. лит., 1975. - С. 447-483.

2. Бахтин, М. М. Собрание сочинений : науч. издание / М. М. Бахтин.-М.: Русские словари, 1996-Т. 6 : Проблемы поэтики Достоевского. Работы 1960-х-1970-х гг. : науч. изд.. - 2002. $800 \mathrm{c}$.

3. Бахтин, М. М.Формы времени и хронотопа в романе: очерки по исторической поэтике // Бахтин М. М. Вопросы литературы и эстетики. - М.: Худож. лит., 1975. - С. 234-407. Режим доступа : http://philologos.narod.ru/bakhtin/ hronotop/hronmain.html.

4. Гессе Г. Собрание сочинений в 4-х томах [Текст] / Г. Гессе; пер. с нем. - СПб.: Северо-запад, 1994. - T.2.

5. Гессе Г. Собрание сочинений в 4-х томах [Текст] / Г. Гессе; пер. с нем. - СПб.: Северо-запад, 1994. - T.3.

6. Гессе Г. Собрание сочинений в 4-х томах [Текст] / Г. Гессе; пер. с нем. - СПб.: Северо-запад, 1994. - T.4.

7. $\quad$ Гессе Г. Степной волк [Текст] / Г. Гессе; пер. с нем. - Спб, Азбука-классика, 2004.

8. Гессе Г. Сиддхардтха [Текст] / Г. Гессе; пер. с нем. Н Федоровской. - М.:АСТ, 2009.

\section{References (transliteration):}

1. Bakhtin, M. M. Voprosy literatury i estetiki. Issledovaniya raznykh let / M. M. Bakhtin. - M.: Khudozh. lit., 1975. - S. 447-483.

2. Bakhtin, M. M. Sobranie sochinenii : nauch. izdanie / M. M. Bakhtin.-M.: Russkie slovari, 1996 T. 6 : Problemy poetiki Dostoevskogo. Raboty 1960-kh-1970-kh gg. : nauch. izd.. - 2002. - $800 \mathrm{~s}$.

3. Bakhtin, M. M.Formy vremeni i khronotopa v romane: ocherki po istoricheskoi poetike // Bakhtin M. M. Voprosy literatury i estetiki. - M.: Khudozh. lit., 1975. - S. 234-407. - Rezhim dostupa : http://philologos.narod.ru/bakhtin/ hronotop/hronmain.html.

4. Gesse G. Sobranie sochinenii v 4-kh tomakh [Tekst] / G. Gesse; per. s nem. - SPb.: Severo-zapad, 1994. - T.2.

5. Gesse G. Sobranie sochinenii v 4-kh tomakh [Tekst] / G. Gesse; per. s nem. - SPb.: Severo-zapad, 1994. - T.3.

6. Gesse G. Sobranie sochinenii v 4-kh tomakh [Tekst] / G. Gesse; per. s nem. - SPb.: Severo-zapad, 1994. - T.4.

7. Gesse G. Stepnoi volk [Tekst] / G. Gesse; per. s nem. - Spb, Azbuka-klassika, 2004.

8. Gesse G. Siddkhardtkha [Tekst] / G. Gesse; per. s nem. N Fedorovskoi. - M.:AST, 2009. 